\title{
A Novel Artificial Intelligent Based Message Authentication Technique in Mobile Communications
}

\author{
Chandan Koner, Member, IACSIT, Pijush Kanti Bhattacharjee, Member, IACSIT, \\ Chandan Tilak Bhunia and Ujjwal Maulik
}

\begin{abstract}
Authentication of mobile subscriber's messages is a challenging issue for future researchers due to increasing security threats and attacks. Next generation mobile communication system has been developed for introducing several new messaging systems having increased volume of data. In the entire authentication techniques in mobile communications, the authenticity of a subscriber is checked by the server or switch at the starting time up of communication (call). These authentication techniques are based on application of cryptographic algorithms and functions for subscriber's authentication, but do not provide any message authentication method. In this paper, we propose an artificial intelligence based subscriber message authentication scheme. Message server performs a feasibility study of subscriber writing characteristics i.e. writing habit or style from subscriber's past messages. It assigns different relative grades according to the appearance in the past messages i.e. frequency of sentences, idioms with salutation words and phrasal verbs appearing like most frequently, more frequently, less frequently used sentences, idioms with salutations and phrasal verbs in those messages. It ascertains the theory of artificial intelligence and thereof derives fuzzy sets from the relative grades which are obtained from number of occurrence of those sentences or idioms or phrasal verbs in a message. Now applying fuzzy operations on fuzzy sets, the server or switch validates the authenticity of a subscriber. This paper also reports how human intelligence can be efficiently introduced to a message server for checking authenticity of the subscribers.
\end{abstract}

Index Terms-Artificial Intelligence, Fuzzy Set, Fuzzy Operation, Message Server, Message Authentication.

Chandan Koner is an Assistant Professor in the Department of Computer Science and Engineering, Bengal Institute of Technology and Management, Santiniketan, P.O. Doranda, West Bengal, Pin-731236, India. He is pursuing PhD course. He is Member of IACSIT, IEEE, CSTA and IAENG. (phone: +91-9434535556; email: chandan_durgapur@yahoo.com).

Pijush Kanti Bhattacharjee is an Assistant Professor in the Department of Electronics and Communication Engineering, Bengal Institute of Technology and Management, Santiniketan, P.O. Doranda, West Bengal, Pin-731236, India. He was an Ex Asssitant Director in the Department of Telecommunications (DoT), Government of India, India. He is a Member of IACSIT, IAENG, CSTA, IAPQR, ISTE and IE.

(phone: +91-33-25954148; email: pijushbhatta 6@hotmail.com)

Chandan Tilak Bhunia is a Director, Bengal Institute of Technology and Management, Santiniketan, P.O. Doranda, West Bengal, Pin-731236, India. $\mathrm{He}$ is a Senior Member of IEEE, FIE (I) and FIETE.

(phone: +91-9434033157; email: ctbhunia@vsnl.com)

Ujjwal Maulik is currently a Professor in the Department of Computer Science and Technology, Jadavpur University, Kolkata, India. He is a Senior Member of IEEE and FIE(I).

(phone: +91-33-24131766; email: ujjwal_maulik@yahoo.com).

\section{INTRODUCTION}

Mobile communications [1]-[3] are upgraded to next generation for providing real time basis and secure service to subscriber messages.

Many messaging systems like sms, mms (Multi Media Message Service), paging, email etc are introducing in mobile communications technology. With advancement of commerce and trades like M- (Mobile) or E-Commerce, MTrade, M-Booking etc, the subscriber needs more stable and secure message service where messages are consisting of rich set having context and valuable data. In mobile communications, the message server provides storage services, operational support, routing and delivering to the destination port for the subscriber's message service.

In traditional mobile network, the authenticity of a subscriber [2] is only checked by the server at the time of setting up the communication or call. The server checks the genuineness of a subscriber by applying cryptographic algorithms and functions [4], but the authenticity of the subscriber messages are not checked by the server or switch. So the subscriber valuable data and information can be corrupted or hacked by an intruder during the transmission of message. To solve this problem, we construct an artificial intelligence based subscriber message authentication technique where the message server will check the authenticity of a subscriber by applying artificial intelligence on subscriber message after receiving of several subscriber messages.

Artificial Intelligence (AI) is a theory based on uncertainty. Fuzzy operations [5] can be performed for taking decision in AI based application. AI can be applied in such applications which are based on uncertainties like vagueness, ambiguity and imprecision. Subscriber message writing characteristics is also based on uncertainties. This provides a research challenge for application of AI on subscriber authentication. We propose to use parameter of subscriber's writing habit. It means which sentences, idioms, phrasal verbs are used with most frequently, more frequently, less frequently by the subscriber. By the theory of AI, different relative grade can be assigned for most frequently; more frequently, less frequently used word groups or sentences considering the frequency of those word groups or sentences in messages. Fuzzy sets may then be derived by relative grade and number of occurrence of those sentences, idioms, phrasal verbs in a message. Then applying fuzzy operations on fuzzy sets, authenticity of subscriber can be verified. 
In this paper, we propose an Artificial Intelligence (AI) based subscriber message authentication scheme that will check the authenticity of a subscriber by fuzzy operation on fuzzy sets which are derived from subscriber's earlier messages. The earlier or past messages of the subscriber are stored in database of the server or switch, which ultimately indicates to measure this authentication technique.

\section{Proposed Message Authentication Technique}

Proposed AI based authentication scheme can be applied to mobile communications network to provide safe and secure message transfer services. It is a collection of two different phases, namely, Subscriber Enrollment Phase and Subscriber Authentication Phase. These two phases are explained below.

\section{A. Subscriber Enrollment Phase}

In subscriber enrollment phase, the subscriber is enrolled to a particular message server (AAA) or switch belonging to the network. This phase is executed only once for one subscriber.

MSE1: The subscriber sends an application request to the authority concerned (mobile service provider) for new SIM.

MSE2: After receiving the request, the authority asks to submit his twenty different past messages.

MSE3: The subscriber sends his twenty different past messages to the authority.

MSE4: After receiving the messages, authority examines those messages thoroughly and performs a feasibility study of writing habit of a subscriber from those messages. The authority records the followings,

(i) Which sentences (including proverbs) are most frequently, more frequently and less frequently are used by the subscriber for writing a message?

(ii) Which idioms (including salutation words and subscription) are most frequently, more frequently and less frequently are used by the subscriber for writing a message?

(iii) Which phrasal verbs are most frequently, more frequently and less frequently are used by the subscriber for writing a message?

MSE5: The authority uses three databases in message server for storing the above subscriber writing habit. The first database, $D_{S}$ stores the subscriber most frequently, more frequently and less frequently used sentences (including proverbs) and theirs corresponding relative grades. The first row, $\mathrm{D}_{\mathrm{SR} 1}$ of $\mathrm{D}_{\mathrm{S}}$, stores the most frequently used sentences and their relative grade which is assigned by 0.9 . The second row, $\mathrm{D}_{\mathrm{SR} 2}$ of $\mathrm{D}_{\mathrm{S}}$, stores the more frequently used sentences and their relative grade which is assigned by 0.6. The third row, $\mathrm{D}_{\mathrm{SR} 3}$ of $\mathrm{D}_{\mathrm{S}}$, stores the less frequently used sentences and their relative grade which is assigned by 0.3 .

The second database, $\mathrm{D}_{\text {I }}$ stores the most frequently, more frequently and less frequently used idioms (including salutation words and subscription) and theirs corresponding relative grades. The first row, $\mathrm{D}_{\text {IR } 1}$ of $\mathrm{D}_{\mathrm{I}}$, stores the most frequently used idioms and their relative grade which is assigned by 0.9 . The second row, $\mathrm{D}_{\mathrm{IR} 2}$ of $\mathrm{D}_{\mathrm{I}}$ stores the more frequently used idioms and their relative grade which is assigned by 0.6 . The third row, $\mathrm{D}_{\mathrm{IR} 3}$ of $\mathrm{D}_{\mathrm{I}}$, stores the less frequently used idioms and their relative grade which is assigned by 0.3 .

The third database, $D_{P}$ stores the most frequently, more frequently and less frequently used phrasal verbs and theirs corresponding relative grades. The first row, $D_{P R 1}$ of $D_{P}$, stores the most frequently used phrasal verbs and their relative grade which is assigned by 0.9 . The second row, $\mathrm{D}_{\mathrm{PR} 2}$ of $\mathrm{D}_{\mathrm{P}}$, stores the more frequently used phrasal verbs and their relative grade which is assigned by 0.6 . The third row, $\mathrm{D}_{\mathrm{PR} 3}$ of $\mathrm{D}_{\mathrm{P}}$, stores the less frequently used phrasal verbs and their relative grade which is assigned by 0.3 .

MSE6: If the authority does not get sufficient information, it sends a request to the subscriber for sending other different past messages. Then the authority executes the above steps again to create a novel database.

\section{B. Subscriber Authentication Phase}

When a subscriber requests for sending a message, $M$, the server receives the $M$ and counts number of sentences (including salutation and subscription), $\mathrm{n}$ in the $\mathrm{M}$. Then server scans $\mathrm{M}$ and executes the following operations,

MSA1: Finds the matched sentences within the rows $\mathrm{D}_{\mathrm{SR} 1 \text {, }}$ $\mathrm{D}_{\mathrm{SR} 2}, \mathrm{D}_{\mathrm{SR} 3}$ of $\mathrm{D}_{\mathrm{S}}$ and $\mathrm{M}$. Let the number of matched sentences in $\mathrm{D}_{\mathrm{SR} 1}, \mathrm{D}_{\mathrm{SR} 2}$ and $\mathrm{D}_{\mathrm{SR} 3}$ are $\mathrm{x} 1$, y1and $\mathrm{z} 1$ respectively.

MSA1.1: Calculates, a1 $=(0.9 \times \mathrm{x} 1) / \mathrm{n}, \mathrm{b} 1=(0.6 \times \mathrm{y} 1) / \mathrm{n}$ and $\mathrm{c} 1=(0.3 \times \mathrm{z} 1) / \mathrm{n}$.

The membership functions of a fuzzy set F1 can be defined as follows,

$\mu_{\mathrm{F} 1}(\mathrm{a} 1)=(0.9 \times \mathrm{x} 1) / \mathrm{n}, \mu_{\mathrm{F} 1}(\mathrm{~b} 1)=(0.6 \times \mathrm{y} 1) / \mathrm{n}, \mu_{\mathrm{F} 1}(\mathrm{c} 1)=$ $(0.3 \times \mathrm{z} 1) / \mathrm{n}$

Hence, $\mathrm{F} 1=\{(\mathrm{a} 1,(0.9 \times \mathrm{x} 1) / \mathrm{n}),(\mathrm{b} 1,(0.6 \times \mathrm{y} 1) / \mathrm{n}),(\mathrm{c} 1$, $(0.3 \times \mathrm{z} 1) / \mathrm{n})\}$

MSA2: Finds the matched idioms within the rows $D_{I R 1}$, $\mathrm{D}_{\mathrm{IR} 2}, \mathrm{D}_{\mathrm{IR} 3}$ of $\mathrm{D}_{\mathrm{I}}$ and $\mathrm{M}$. Let the number of matched idioms in $\mathrm{D}_{\mathrm{IR} 1}, \mathrm{D}_{\mathrm{IR} 2}$ and $\mathrm{D}_{\mathrm{IR} 3}$ are $\mathrm{x} 2, \mathrm{y} 2$ and $\mathrm{z} 2$ respectively.

MSA2.1: Calculates, $\mathrm{a} 2=(0.9 \times \mathrm{x} 2) / \mathrm{n}, \mathrm{b} 2=(0.6 \times \mathrm{y} 2) / \mathrm{n}$ and $\mathrm{c} 2=(0.3 \times \mathrm{z} 2) / \mathrm{n}$

The membership functions of a fuzzy set F2 can be defined as follows,

$\mu_{\mathrm{F} 2}(\mathrm{a} 2)=(0.9 \times \mathrm{x} 2) / \mathrm{n}, \mu_{\mathrm{F} 2}(\mathrm{~b} 2)=(0.6 \times \mathrm{y} 2) / \mathrm{n}$, $\mu_{\mathrm{F} 2}(\mathrm{c} 2)=(0.3 \times \mathrm{z} 2) / \mathrm{n}$

Hence, $\mathrm{F} 2=\{(\mathrm{a} 2,(0.9 \times \mathrm{x} 2) / \mathrm{n}),(\mathrm{b} 2,(0.6 \times \mathrm{y} 2) / \mathrm{n}),(\mathrm{c} 2$, $(0.3 \times \mathrm{z} 2) / \mathrm{n})\}$

MSA3: Finds the matched phrasal verbs within the rows $\mathrm{D}_{\mathrm{PR} 1}, \mathrm{D}_{\mathrm{PR} 2}, \mathrm{D}_{\mathrm{PR} 3}$ of $\mathrm{D}_{\mathrm{P}}$ and $\mathrm{M}$. Let the number of matched phrasal verbs in $\mathrm{D}_{\mathrm{PR} 1}, \mathrm{D}_{\mathrm{IR} 2}, \mathrm{D}_{\mathrm{IR} 3}$ are $\mathrm{x} 3, \mathrm{y} 3$ and $\mathrm{z} 3$ respectively.

MSA3.1: Calculates, $\mathrm{a} 3=(0.9 \times \mathrm{x} 3) / \mathrm{n}, \mathrm{b} 3=(0.6 \times \mathrm{y} 3) / \mathrm{n}$ and $\mathrm{c} 3=(0.3 \times \mathrm{z} 3) / \mathrm{n}$

The membership functions of a fuzzy set F3 can be defined as follows,

$\mu_{\mathrm{F} 3}(\mathrm{a} 3)=(0.9 \times \mathrm{x} 3) / \mathrm{n}, \mu_{\mathrm{F} 3}(\mathrm{~b} 3)=(0.6 \times \mathrm{y} 3) / \mathrm{n}$,

$\mu_{\mathrm{F} 3}(\mathrm{c} 3)=(0.3 \times \mathrm{z} 3) / \mathrm{n}$

Hence, F3 $=\{(\mathrm{a} 3,(0.9 \times \mathrm{x} 3) / \mathrm{n}),(\mathrm{b} 3,(0.6 \times \mathrm{y} 3) / \mathrm{n}),(\mathrm{c} 3$, $(0.3 \times \mathrm{z} 3) / \mathrm{n})\}$

MSA4: Computes,

MSA4.1: $\mu \mathrm{F} 1 \cap_{\mathrm{F} 2} \cap_{\mathrm{F} 3}(\mathrm{a})=\min \left\{\mu_{\mathrm{F} 1}(\mathrm{a} 1), \mu_{\mathrm{F} 2}(\mathrm{a} 2), \mu_{\mathrm{F} 3}\right.$ (a3)\}

MSA4.2: $\mu_{\mathrm{F} 1 \cup \mathrm{F} 2 \cup \mathrm{F} 3}(\mathrm{a})=\max \left\{\mu_{\mathrm{F} 1}(\mathrm{a} 1), \mu_{\mathrm{F} 2}(\mathrm{a} 2), \mu_{\mathrm{F} 3}\right.$

(a3)\}

MSA4.3: If $\mu_{\mathrm{F} 1} \cap_{\mathrm{F} 2} \cap_{\mathrm{F} 3}(\mathrm{a}) \geq 0.09$ and 
$\mu_{\mathrm{F} 1} \cup \mathrm{F} 2 \cup \mathrm{F}(\mathrm{a}) \geq 0.18$, server ensures that the subscriber is authentic. Else executes the next steps. (b3)\}

MSA4.4: $\mu_{\mathrm{F} 1} \cap_{\mathrm{F} 2} \cap_{\mathrm{F} 3}(\mathrm{~b})=\min \left\{\mu_{\mathrm{F} 1}(\mathrm{~b} 1), \mu_{\mathrm{F} 2}(\mathrm{~b} 2), \mu_{\mathrm{F} 3}\right.$

MSA4.5: $\mu_{\mathrm{F} 1 \cup \mathrm{F} 2 \cup \mathrm{F} 3}(\mathrm{~b})=\max \left\{\mu_{\mathrm{F} 1}(\mathrm{~b} 1), \mu_{\mathrm{F} 2}(\mathrm{~b} 2), \mu_{\mathrm{F} 3}\right.$ (b3) $\}$

MSA4.6: If $\mu \mathrm{F} 1 \cap_{\mathrm{F} 2} \cap_{\mathrm{F} 3}$ (b) $\geq 0.045$ and

$\mu_{\mathrm{F} 1} \cup$ F2 $\cup$ F3 $(b) \geq 0.09$, then server ensures that the subscriber is authentic. Else executes the next steps.

MSA4.7: $\mu \mathrm{F} 1 \cap_{\mathrm{F} 2} \cap_{\mathrm{F} 3}(\mathrm{c})=\min \left\{\mu_{\mathrm{F} 1}(\mathrm{c} 1), \mu_{\mathrm{F} 2}(\mathrm{c} 2), \mu_{\mathrm{F} 3}\right.$ (c3)\}

MSA4.8: $\mu_{\mathrm{F} 1 \cup \mathrm{F} 2 \cup \mathrm{F}_{3}}(\mathrm{c})=\max \left\{\mu_{\mathrm{F} 1}(\mathrm{c} 1), \mu_{\mathrm{F} 2}(\mathrm{c} 2), \mu_{\mathrm{F} 3}\right.$ (c3)\}

MSA4.9: If $\mu_{\mathrm{F} 1} \cap_{\mathrm{F} 2} \cap_{\mathrm{F} 3}(\mathrm{c}) \geq 0.03$ and

$\mu_{\mathrm{F} 1} \cup \mathrm{F} 2 \cup \mathrm{F}_{3}(\mathrm{c}) \geq 0.06$, then server ensures that the subscriber is authentic.

If no conditions are matched, then server ensures that the subscriber is unauthentic and ignores the message of a subscriber. Server sends an authentication failure message to the subscriber

\section{RESULTS AND DISCUSSION}

Suppose after the feasibility study of subscriber writing habit from subscriber past twenty different messages, server stores the following data in three databases,

The sentences stored in $\mathrm{D}_{\mathrm{SR} 1}$ of $\mathrm{D}_{\mathrm{S}}$ are,

A lot of thanks for your sweet letter; Patience is bitter but its fruit is sweet; I am fine; Don't worry, keep in touch; What about you; My parents are better; Take care; No more to day; However, I may be excused from writing more at present; My love to you; I look after the matter; Your active cooperation is highly needed; Waiting for you reply;

The sentences stored in $\mathrm{D}_{\mathrm{SR} 2}$ of $\mathrm{D}_{\mathrm{S}}$ are,

Your sweet letter just anchored the shore of my heart; Jack of all trades, master of none; My days are going as usual; How are you; My parents are ok; That's all, from me; Nothing more for the present; My love and blessing to you; I am taking all of the responsibilities; Please take necessary step of my request; As soon as you can, please write to me; Respect to you;

The sentences stored in $\mathrm{D}_{\mathrm{SR} 3}$ of $\mathrm{D}_{\mathrm{S}}$ are,

I have just received your letter; A tree is known by its fruit; I am pretty well now; What about you right now; My parents are fine; Above all, be careful of your health; My respect to your parents my love to you; Now I am not in a position to write any more; I am trying heart and soul; You help in this matter is highly needed; Thanking you; Please do come;

The idioms and salutation words stored in $\mathrm{D}_{\mathrm{IR} 1}$ of $\mathrm{D}_{\mathrm{I}}$ are,

My dear; Respected sir; heart and soul; all in all; at last; By the bye; call to mind; dead against; to the contrary; out of order; in force; now and then; Yours ever; Yours faithfully;

The idioms and salutation words stored in DIR2 of DI are,

Dear friend; Dear sir; at all; By the by; tooth and nail; flesh and blood; head and hears; in a hurry; in order to; round the clock; out of date; of course; null and void; Yours friend; Yours sincerely;
The idioms and salutation words stored in $\mathrm{D}_{\mathrm{IR} 3}$ of $\mathrm{D}_{\mathrm{I}}$ are,

Dear; Sir; by leaps and bounds; Above all; as if; by chance; by and large; carry the day; From A to Z; hard and fast; in time; on the contrary; I remain, yours ever; I remain, yours faithfully;

The phrasal verbs stored in $\mathrm{D}_{\mathrm{PR} 1}$ of $\mathrm{D}_{\mathrm{P}}$ are,

act under; call up; kept in; come by; deal with; get over; get through; go through; hang on; keep in; look over; tell of; run away; see off;

The phrasal verbs stored in $\mathrm{D}_{\mathrm{PR} 2}$ of $\mathrm{D}_{\mathrm{P}}$ are,

break up; bear with; come by; carry on; draw in; give out; go beyond; keep at; lay before; make of; take over; run into; see about; work out;

The phrasal verbs stored in $\mathrm{D}_{\mathrm{PR} 3}$ of $\mathrm{D}_{\mathrm{P}}$ are,

act on; break through; come to; carry with; drive away; go on; fall in; keep on; put by; look after; make up; put up with; take off; work on;

Suppose the subscriber sends the following message, M, User Message $(\mathrm{M})=$

Dear friend Bob,

Your sweet letter just anchored the shore of my heart. I can't call up when I received your last letter. I am happy to know that you kept in your research work by heart and soul. I come by your mail attachment where you tell of a problem of fuzzy logic. You wrote that you have not got any solution at all. I will go through the attachment and work out the problem as soon as possible. Don't worry, keep in touch. Patience is bitter, but its fruit is sweet. You don't break up your work.

By the by, my research work is progressing by leaps and bounds. I hope that my work will come to light very soon.

I am pretty well now. What about you right now? My parents are fine. What about the health of your parents? You look after your parents.

Above all, be careful of your health. My respect to your parents my love to you.

\section{I remain, yours ever,}

Alice

So, the number of sentences (including salutation and subscription), $\mathrm{n}=20$.

Hence, the matched sentences in $\mathrm{D}_{\mathrm{SR} 1}, \mathrm{D}_{\mathrm{SR} 2}, \mathrm{D}_{\mathrm{SR} 3}$ are,

$\mathrm{D}_{\mathrm{SR} 1}$ : Patience is bitter but its fruit is sweet; Don't worry, keep in touch;

$\mathrm{D}_{\mathrm{SR} 2}$ : Your sweet letter just anchored the shore of my heart;

$\mathrm{D}_{\mathrm{SR} 3}$ : I am pretty well now; What about you right now? ; My parents are fine; Above all, be careful of your health; My respect to your parents my love to you;

So, the number of matched sentences in $\mathrm{D}_{\mathrm{SR} 1}, \mathrm{D}_{\mathrm{SR} 2}, \mathrm{D}_{\mathrm{SR} 3}$ are $\mathrm{x} 1=2, \mathrm{y} 1=1$ and $\mathrm{z} 1=5$ respectively.

Therefore, $\mathrm{a} 1=.09, \mathrm{~b} 1=.03$ and $\mathrm{c} 1=.075$

Hence the matched idioms in $\mathrm{D}_{\mathrm{IR} 1}, \mathrm{D}_{\mathrm{IR} 2}, \mathrm{D}_{\mathrm{IR} 3}$ are,

$\mathrm{D}_{\mathrm{IR} 1}$ : heart and soul; $\mathrm{D}_{\mathrm{IR} 2}$ : at all; Dear friend; By the by; $\mathrm{D}_{\mathrm{IR} 3}$ : by leaps and bounds; Above all, I remain, yours ever;

So, the number of matched idioms in $\mathrm{D}_{\mathrm{IR} 1}, \mathrm{D}_{\mathrm{IR} 2}, \mathrm{D}_{\mathrm{IR} 3}$ are $\mathrm{x} 2=1, \mathrm{y} 2=3, \mathrm{z} 2=3$ respectively.

Therefore, $\mathrm{a} 2=.045, \mathrm{~b} 2=.09$ and $\mathrm{c} 2=.045$

Hence the matched phrasal verbs in $\mathrm{D}_{\mathrm{PR} 1}, \mathrm{D}_{\mathrm{PR} 2}, \mathrm{D}_{\mathrm{PR} 3}$ are:

$\mathrm{D}_{\mathrm{PR} 1}$ : call up; kept in; come by; tell of; go through; $\mathrm{D}_{\mathrm{PR} 2}$ : 
work out; break up; $\mathrm{D}_{\mathrm{PR} 3}$ : come to; look after;

So, the number of matched phrasal verbs in $D_{P R 1} D_{P R 2}$ $\mathrm{D}_{\mathrm{PR} 3}$ are $\mathrm{x} 3=5, \mathrm{y} 3=2, \mathrm{z} 3=2$ respectively.

Therefore, $\mathrm{a} 3=.225, \mathrm{~b} 3=.06$ and $\mathrm{c} 3=.03$

Now, $\mu_{\mathrm{F} 1} \cap_{\mathrm{F} 2} \cap_{\mathrm{F} 3}(\mathrm{a})=\min \{0.09,0.045,0.225\}=0.045$

and $\mu \mathrm{F} 1 \cup \mathrm{F} 2 \cup \mathrm{F} 3(\mathrm{a})=\max \{0.09,0.045,0.225\}=0.225$

As $\mu_{\mathrm{F} 1} \cap_{\mathrm{F} 2} \cap_{\mathrm{F} 3}(\mathrm{a}) \geq 0.09$ and $\mu_{\mathrm{F} 1} \cup \mathrm{F} 2 \cup \mathrm{F} 3$ (a) $\geq 0.18$ are not true so the server executes the next steps.

In next step, $\mu_{\mathrm{F} 1} \cap_{\mathrm{F} 2} \cap_{\mathrm{F} 3}(\mathrm{~b})=\min \{0.03,0.09,0.06\}=$ 0.03 and $\mu_{\mathrm{F} 1} \cup \mathrm{F}_{2} \cup \mathrm{F}_{3}(\mathrm{~b})=\max \{0.03,0.09,0.06\}=0.09$

As $\mu_{\mathrm{F} 1} \cap_{\mathrm{F} 2} \cap_{\mathrm{F} 3}(\mathrm{~b}) \geq 0.045$ and $\mu_{\mathrm{F} 1} \cup \mathrm{F} 2 \cup \mathrm{F}_{3}(\mathrm{~b}) \geq 0.09$ are not true so the sever executes the next steps.

In this, $\mu_{\mathrm{F} 1} \cap_{\mathrm{F} 2} \cap_{\mathrm{F} 3}(\mathrm{c})=\min \{0.075,0.045,0.03\}=0.03$ and $\mu_{\mathrm{F} 1} \cup \mathrm{F} \cup \mathrm{F}_{\mathrm{F} 3}(\mathrm{c})=\max \{0.075,0.045,0.03\}=0.075$

As $\mu_{\mathrm{F} 1} \cap_{\mathrm{F} 2} \cap_{\mathrm{F} 3}$ (c) $\geq 0.03$ and $\mu_{\mathrm{F} 1} \cup \mathrm{F} 2 \cup \mathrm{F}_{3}(\mathrm{c}) \geq 0.06$ are true so the sever ensures that the subscriber is authentic.

Now suppose the server receives the following message instead of the previous message and the above procedure has to be carried out for checking the authentication of the subscriber under this message scheme,

\section{Dear friend Bob,}

Your sweet letter just anchored the shore of my heart. I can't remember when I received your last letter. I am happy to know that you kept in your research work. I come by your mail attachment where you describe a problem of fuzzy logic. You wrote that you can't solve it. I have attached the solution of your problem. Don't worry, keep in touch. I am always with you. You don't break up your work.

By the by, my research work is going on very well. I hope that my work will come to light very soon.

I am pretty well now. What about you right now? My parents are fine. What about the health of your parents? You look after your parents.

Above all, be careful of your health. Take my love.

Only yours, Alice

So, the number of sentences (including salutation and subscription), $\mathrm{n}=20$.

Hence, the matched sentences in $\mathrm{D}_{\mathrm{SR} 1}, \mathrm{D}_{\mathrm{SR} 2}, \mathrm{D}_{\mathrm{SR} 3}$ are,

$\mathrm{D}_{\mathrm{SR} 1}$ : Don't worry, keep in touch;

$\mathrm{D}_{\mathrm{SR} 2}$ : Your sweet letter just anchored the shore of my heart;

$\mathrm{D}_{\mathrm{SR} 3}$ I I am pretty well now; What about you right now? ; My parents are fine; Above all, be careful of your health;

So, the number of matched sentences in $\mathrm{D}_{\mathrm{SR} 1}, \mathrm{D}_{\mathrm{SR} 2}, \mathrm{D}_{\mathrm{SR} 3}$ are $\mathrm{x} 1=1, \mathrm{y} 1=1$ and $\mathrm{z} 1=4$ respectively.

Therefore, $\mathrm{a} 1=.045, \mathrm{~b} 1=.03$ and $\mathrm{c} 1=.06$

Hence the matched idioms in $\mathrm{D}_{\mathrm{IR} 1}, \mathrm{D}_{\mathrm{IR} 2}, \mathrm{D}_{\mathrm{IR} 3}$ are,

$D_{I R 1}$ : Null $D_{I R 2}$ : Dear friend; By the by; $D_{I R 3}$ : Above all

So, the number of matched idioms in $\mathrm{D}_{\mathrm{IR} 1}, \mathrm{D}_{\mathrm{IR} 2}, \mathrm{D}_{\mathrm{IR} 3}$ are $\mathrm{x} 2=0, \mathrm{y} 2=2, \mathrm{z} 2=1$ respectively.

Therefore, $\mathrm{a} 2=0, \mathrm{~b} 2=.06$ and $\mathrm{c} 2=.015$

Hence the matched phrasal verbs in $\mathrm{D}_{\mathrm{PR} 1}, \mathrm{D}_{\mathrm{PR} 2}, \mathrm{D}_{\mathrm{PR} 3}$ are:

$\mathrm{D}_{\mathrm{PR} 1}$ :_kept_in; come by; $\mathrm{D}_{\mathrm{PR} 2}$ : break up; $\mathrm{D}_{\mathrm{PR} 3}$ : come to; look after;

So, the number of matched phrasal verbs in $D_{\mathrm{PR} 1} \mathrm{D}_{\mathrm{PR} 2}$ $\mathrm{D}_{\mathrm{PR} 3}$ are $\mathrm{x} 3=2, \mathrm{y} 3=1, \mathrm{z} 3=2$ respectively.

Therefore, $\mathrm{a} 3=.09, \mathrm{~b} 3=.03$ and $\mathrm{c} 3=.03$
Now, $\mu_{\mathrm{F} 1} \cap_{\mathrm{F} 2} \cap_{\mathrm{F} 3}(\mathrm{a})=\min \{0.045,0,0.09\}=0$ and

$\mu_{\mathrm{F} 1} \cup \mathrm{F} 2 \cup$ F3 $(\mathrm{a})=\max \{0.045,0,0.09\}=0.09$

As $\mu_{\mathrm{F} 1} \cap_{\mathrm{F} 2} \cap_{\mathrm{F} 3}(\mathrm{a}) \geq 0.09$ and $\mu_{\mathrm{F} 1} \cup \mathrm{F} 2 \cup \mathrm{F} 3(\mathrm{a}) \geq 0.18$ are not true so the server executes the next steps.

In next step, $\mu_{\mathrm{F} 1} \cap_{\mathrm{F} 2} \cap_{\mathrm{F} 3}(\mathrm{~b})=\min \{0.03,0.06,0.03\}=$ 0.03 and $\mu_{\mathrm{F} 1} \cup \mathrm{F} 2 \cup \mathrm{F} 3(\mathrm{~b})=\max \{0.03,0.06,0.03\}=0.06$

As $\mu_{F 1} \cap_{F 2} \cap_{F 3}(b) \geq 0.045$ and $\mu_{F 1} \cup$ F2 $\cup$ F3 $(b) \geq 0.09$ are not true so the sever executes the next steps.

So, $\mu_{\mathrm{F} 1} \cap_{\mathrm{F} 2} \cap_{\mathrm{F} 3}(\mathrm{c})=\min \{0.06,0.015,0.03\}=0.015$

and $\mu \mathrm{F} 1 \cup \mathrm{F}_{2} \cup \mathrm{F}_{3}(\mathrm{c})=\max \{0.06,0.015,0.03\}=0.06$

As $\mu_{\mathrm{F} 1} \cap_{\mathrm{F} 2} \cap_{\mathrm{F} 3}(\mathrm{c}) \geq 0.03$ and $\mu_{\mathrm{F} 1} \cup \mathrm{F} 2 \cup \mathrm{F}_{3}(\mathrm{c}) \geq 0.06$ are not true. So the sever ensures that the subscriber is unauthentic and ignores the message.

\section{Advantages of THE Proposed AUthentiCATION TECHNIQUE}

This technique is highly efficient due to artificial intelligence is applied for subscriber message authentication system.

The characteristics of this authentication scheme are,

(i) This mobile subscriber message authentication technique enjoys the advantages of artificial intelligence and fuzzy theory, so it is a unique one.

(ii) Artificial intelligence is efficiently employed to the server and subsequently it takes part to authenticate correct subscribers.

(iii) Authenticity is decided by the subscriber's writing habit.

(iv) No cryptography algorithm or any complex functions are applied for this authentication system.

(v) Flexible simple fuzzy operations are performed on fuzzy set for the authentication decision.

(vi) This authentication technique ensures result with in a real time basis.

\section{CONCLUSION}

In our proposed artificial intelligence based technique, message authentication scheme is developed for the subscriber of any mobile network (3-G or any advanced level). A novel artificial intelligence is introduced to the server or switch for this authentication purpose. This technique enables to work within a real time basis for the present as well as the next generation wireless communication networks.

\section{REFERENCES}

[1] William C. Y. Lee, Wireless and Cellular Communications, 3rd Edition McGraw Hill Publishers 2008.

[2] C. Koner, P. K. Bhattacharjee, C. T. Bhunia, U Maulik, "A Novel Approach for Authentication Technique in Mobile Communications", International Journal of Computer Theory and Engineering, Singapore, vol. 1, no. 3, 2009, pp. 225-229.

[3] D. Goodman, "Cellular Packet Communication", IEEE Transactions on Communications, vol. 38, no. 8, pp. 1272-1280, August 1990.

[4] C. T. Bhunia, Information Technology Network and Internet, New Age International Publishers, India, 5th Edition (Reprint), 2006.

[5] Vilem Novak, Jiri Mockor, Irina Perfilieva, Mathematical Principles of Fuzzy Logic, Kluwer Academic Publisher, 2006. 


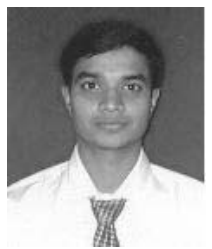

Mr. Chandan Koner did his B.Tech in 2005 and M.Tech in 2007 respectively. He is currently an Assistant Professor in the Department of Computer Science and Engineering, Bengal Institute of Technology and Management, Santiniketan, P.O. Doranda, West Bengal, Pin-731236, India. He is pursuing $\mathrm{PhD}$ course in Computer Science and Engineering from Jadavpur University, Kolkata, India. Mr. Koner is a Member of ISTE, India; IEEE, USA; CSTA, USA; IACSIT, Singapore and IAENG,Hongkong. His research interests include Mobile Communications, Network Security, Data Mining and Sensor Networks etc.

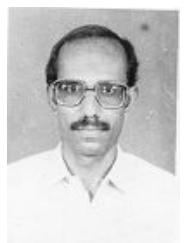

Dr. Pijush Kanti Bhattacharjee is associated with the study of Engineering, Management, Law, Indo-Allopathy, Herbal, Homeopathic and Yogic medicines. He is having qualifications M.E, MBA, MDCTech, A.M.I.E, B.Sc, B.A, LLB, BIASM, CMS, PET, EDT, FWT, DATHRY, B.Mus, KOVID, DH, ACE, FDCI etc. He worked as an Engineer in Department of Telecommunications (DoT), Govt. of India from June 1981 to Jan 2007 (26 years), lastly holding Assistant Director post at RTEC [ER], DoT, Kolkata, India. Thereafter, he started working at IMPS College of Engineering and Technology, Malda, WB, India as an Assistant Professor in Electronics and Communication Engineering Department from Jan,2007 to Feb,2008 and Feb, 2008 to Dec, 2008 at Haldia Institute of Technology, Haldia, WB, India. In Dec, 2008 he joined at Bengal Institute of Technology and Management, Santiniketan, WB, India in the same post and department. He has written two books "Telecommunications India" \& "Computer". He is a Member of IE, ISTE, IAPQR, ARP, IIM, India; CSTA, USA; IACSIT, Singapore and IAENG, Hongkong. His research interests are in Mobile Communications, Image Processing, VLSI, Network Security, Nanotechnology etc.

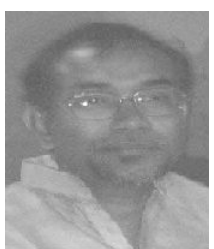

Dr. Chandan Tilak Bhunia did his B. Tech and M Tech in Radio Physics and Electronics in 1982 and 1984, and Ph.D in Computer Science and Engineering. $\mathrm{He}$ is currently Director, Bengal Institute of Technology and Management, Santiniketan, P.O. Doranda, West Bengal, Pin-731236, India. He is a Senior Associate of International Center for Theoretical Physics (ICTP), Italy. Dr. Bhunia is a Fellow of Institution of Electronics and Telecommunication Engineers (IETE) and Institution of Engineers (IE), India, and a Senior Member of Institute of Electrical and Electronics Engineers (IEEE). His research interests include Mobile Communications, Network Security, Computer Networks, Electronics Semiconductors and Multimedia Systems.

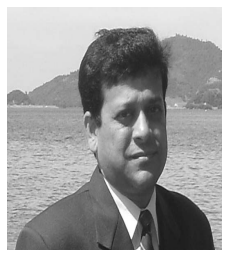

Dr. Ujiwal Maulik did his BS in Physics and Computer Science in 1986 and 1989 respectively, and MS and Ph.D in Computer Science in 1991 and 1997 respectively. $\mathrm{He}$ is currently a Professor in the Department of Computer Science and Technology, Jadavpur University, Kolkata, India. Dr. Maulik received the fellowships from International Center for Pure and Applied Mathematics, CIPA, France, in 1994, 1996 and 2006 and International Center for Theoretical Physics (ICTP), Italy in 2007. Dr. Maulik is also a Fellow of Institution of Electronics and Telecommunication Engineers (IETE) and Institution of Engineers (IE), India, and a Senior Member of Institute of Electrical and Electronics Engineers (IEEE). His research interests include Soft Computing, Pattern Recognition, Data Mining, Bioinformatics, Parallel and Distributed Systems. 